\title{
Tessituras de si: transfigurações do corpo feminino e crítica feminista em Marina Colasanti
}

\author{
Maisa Barbosa da Silva Cordeiro ${ }^{\mathrm{i}}$
}

\begin{abstract}
RESUMO
Neste trabalho analisam-se os contos "Além do bastidor" e "Fio a fio", presentes no livro Uma ideia toda azul (1979), de Marina Colasanti. A contística da autora, em constante diálogo com a mitologia, é elaborada na confluência entre o imaginário coletivo e a subjetividade, percebida no comportamento das personagens frente às vicissitudes das diegeses. Entre as temáticas abordadas por Colasanti estão as relações entre mulheres, sejam elas harmoniosas ou conflituosas. Essas relações são evidenciadas, nos dois contos sobre os quais se debruça este trabalho, por meio das formas de amadurecimento sofridas pelas personagens ao longo das narrativas. Parte-se, neste artigo, especificamente da análise das metáforas do ato de tecer, que se imbricam ao amadurecimento das mulheres representadas e à transfiguração de seus corpos.
\end{abstract}

Palavras-chave: Mulher; transfiguração do corpo; Marina Colasanti.

\begin{abstract}
In this essay I will analyze the short stories "Além do bastidor" and "Fio a fio", present in Marina Colasanti's Uma ideia toda azul (1979). The author's short stories, in a constant dialogue with mythology, are elaborated in the confluence of the collective imaginary and subjectivity, noticed in the behavior of the characters faced with diegetic vices. The correlations between women, be they harmonious or conflicting, are among the themes explored by Colasanti. Those relationships become evident in the two short stories which this essay focuses on through the ways the characters undergo their maturing processes throughout the narratives. This essay departs from an analysis of the metaphors of the act of sewing, which overlap with the process of maturing of the women portrayed in the stories and with the transfiguration of their bodies.
\end{abstract}

Keywords: Women; Transfiguration of the body; Marina Colasanti.

\footnotetext{
i Professora do curso de Letras do Centro Universitário da Grande Dourados. Doutora em Estudos Literários pela Universidade Federal de Mato Grosso do Sul. Mestre em Letras pela Universidade Federal da Grande Dourados. Graduada em Letras pela Universidade Federal da Grande Dourados. http://orcid.org/0000-0003-1352-2214| maysa_bdasilva@yahoo.com.br
} 


\section{INTRODUÇÃO}

Marina Colasanti nasceu em Asmara, capital da Eritreia, em 1937. Migrou para o Brasil com a família em 1948 e aqui permaneceu. É artista plástica, atuou no jornalismo, na publicidade e como tradutora. Enquanto escritora, lançou mais de cinquenta títulos e é ilustradora de boa parte deles. Sua produção literária é bastante premiada. Entre os prêmios que já recebeu estão Jabutis, Grande Prêmio da Crítica da APCA, Biblioteca Nacional para poesia e Portugal Telecom de Literatura 2011. Ainda se tornou hors-concours da Fundação Nacional do Livro Infantil e Juvenil (FNLIJ) após ter sido várias vezes premiada.

Na década de 1980, Colasanti escreve obras não ficcionais sobre a condição da mulher. Entre suas publicações, estão Mulher daqui pra frente, Uma nova mulher e Intimidade Pública, nas quais estão reunidos textos que consistem em respostas às cartas de leitores e leitoras da Revista Nova entre o final da década de 1970 e início de 1980. Nas respostas, a autora reflete acerca dos papéis sociais atribuídos às mulheres. Em um momento importante da expansão do feminismo no Brasil, a década de 1980, Colasanti contribui para a ampliação das discussões sobre papéis de gênero.

Por mais que as publicações de Colasanti sejam bastante estudadas pela crítica literária feminista (No banco de teses da Capes, em busca feita em maio de 2020, encontram-se quarenta e seis trabalhos em nível de mestrado e doutorado com os termos de busca "Marina Colasanti" + "mulher"), que é também o campo do qual parte este trabalho, é importante ressaltar que suas temáticas são bastante plurais e tecem provocações sobre a condição humana.

Em 2015, a autora reúne seus contos de fadas em um livro singular: Mais de cem histórias maravilhosas, em comemoração aos seus 80 anos. Entre os contos, estão os que analisaremos neste trabalho, "Além do bastidor" e "Fio a fio", publicados pela primeira vez na obra Uma ideia toda azul (1979), no qual as narrativas versam sobre problemáticas advindas dos conflitos das relações sociais e sentimentos profundos contraditórios: ciúme, amor, inveja, desejo, entre outros.

As metáforas de Colasanti partem da natureza, de elementos cotidianos ou vinculados às práticas atribuídas, historicamente, às mulheres. Em “Além do bastidor” e "Fio a fio", o ato de tecer é tomado como uma atividade por meio da qual as 
personagens (re)constroem a si próprias. Aliás, metáforas relacionadas ao tear são bastante presentes nos contos de Colasanti. Um dos mais conhecidos, "A moça tecelã", tem como protagonista uma moça que, possuidora de uma máquina de tear, tecia tudo o que desejava e o que fosse necessário para sua sobrevivência. Em seu tear, dava vida aos seres e produzia seu alimento. Um dia, após tanto tecer, sentiu-se solitária e teceu um marido para ser sua companhia. Ele, assim que viu a habilidade da mulher ao tear, decidiu que ela deveria trabalhar o dia todo. Contudo, após um tempo satisfazendo os desejos do marido, ela se percebeu infeliz e decidiu desfazê-lo, puxando uma linha do tecido que o constituía.

Já nas narrativas aqui analisadas, o bordado torna-se metáfora para os conflitos advindos das relações entre irmãs, que, ao passo que bordam, elaboram diferentes maneiras de existir e de conviver com outras mulheres: em cada um dos contos, há apenas duas personagens, e, nos dois, elas são irmãs. As relações representadas são conturbadas em alguns momentos, pois a convivência entre as mulheres é marcada, também, por uma gama de enfrentamentos umas às outras. Suely Costa (2004), em artigo intitulado "Movimentos feministas, feminismos", defende que é um mito supor, a partir da identidade biológica, que mulheres são iguais, e essa crença oculta diversidades, devido ao ideal de sororidade.

Este trabalho, portanto, inscreve-se na ginocrítica, que se propõe a realizar, segundo Eliane Showalter (1994), um estudo do estilo, dos temas, os gêneros, entre outros, nos textos escritos por mulheres. O objetivo, aqui, é verificar, por meio das personagens analisadas, como são elaboradas as relações entre mulheres. Com a ausência de um final especialmente feliz, como é característico dos contos de fadas (COELHO, 1987), "Fio a fio" e "Além do bastidor" são um convite ao entendimento de relações entre mulheres. As personagens-tecelãs se emaranham aos fios e, em narrativas que bebem na mitologia, tecem ativamente sua própria história. Assim, buscar entender as metáforas que permeiam o universo da costura, do bordado e do tecer, atividade historicamente atribuída à mulher, é, também, um modo de entender como essa relação é significada na literatura. 


\section{1. "ALÉM DO BASTIDOR" E "FIO APÓS FIO": TECENDO HISTÓRIAS E CAMINHOS}

"Além do bastidor" e "Fio após fio" são narrativas que giram em torno da relação mulher e tessitura. Nos dois contos, além de toda a trama narrativa fazer diálogo com o bordado, o ato de bordar é intrínseco à reelaboração das próprias personagens, pois devido a ele, elas têm seus corpos transfigurados: a protagonista de "Além do bastidor" é transformada em peça do próprio trabalho, ou seja, ela própria se torna parte do tecido, e a personagem de "Fio a fio" é transformada em aranha ao disputar um manto com a irmã.

Os dois contos têm influxos de narrativas mitológicas. Estas, ao serem retomadas, são reelaboradas de modo a ressignificar a condição e o papel das mulheres. Para tratar de mito, partimos da concepção de Marilena Chauí (2003):

[...] o mito é uma narrativa sobre a origem de alguma coisa (origem dos astros, da terra, dos homens, das plantas, dos animais, do fogo, da água, dos ventos, do bem e do mal, da saúde e da doença, da morte, dos instrumentos de trabalho, das raças, das guerras, do poder, etc.). (CHAUÍ, 2003, p. 43)

Os contos aqui analisados ressignificam, em suas diegeses, narrativas mitológicas ao retomá-las e promover outra atuação da mulher. O processo dialógico travado, então, vai além de mera retomada das narrativas anteriores. Segundo Bakhtin (2017), a orientação dialógica é intrínseca ao discurso, já que este é vivo, e, na escrita de Marina Colasanti, os discursos acerca da mulher presentes nos mitos são palco para o surgimento de novas relações das mulheres com a tessitura, que deixa de ser mera atividade, e se torna ação por meio das quais as mulheres transfiguram a si e aos seus corpos.

"Fio a fio" e "Além do bastidor", publicados pela primeira vez em 1979 então, dialogam com as narrativas mitológicas, mas, também, com o momento histórico no qual os contos são publicados. Para Greicy Bellin (2011): as produções literárias “[...] são também produtos sociais, capazes de dizer muita coisa sobre a época em que foram produzidas" (BELLIN, 2011, p. 10). Assim, as narrativas dos contos revelam um discurso feminista em evidência na passagem da década de 1970 para a década de $1980^{1}$. 
A retomada das narrativas primordiais é feita pelo diálogo com histórias que remetem ao tecer, atividade por meio da qual as mulheres, ao longo da história, vestem os seus, produzem arte e distraem. Para Rodríguez Valle (2012), tradicionalmente, a mulher está associada com o uso da roca, do fio e da tela. Essa associação acaba, também, por demarcar atividades femininas e masculinas: "Es entonces que el hilar y el cuidar las tradiciones se unieron y se convirtieron en labores fundamentales femeninas: tejer hilos y palabras, tejer destinos, mantener la tradición" (VALLE, 2012, p. 3). Mais do que mera confirmação de uma tradição, "Fio a fio" e "Além do bastidor" ressignificam a associação das mulheres ao ato de tecer e esta atividade passa a ser crucial na reconstrução das próprias mulheres e de suas relações.

Os contos de fadas de Marina Colasanti abordam questões associadas ao imaginário coletivo, como é comum aos contos de fadas, mas também representam formas de libertação (FOUCAULT, 2004) dos sujeitos. As narrativas da autora deixam entrever cenas nas quais as personagens representadas modificam seu entorno ao modificarem a si próprias. No que tange aos dois contos aqui analisados, eles evidenciam, ainda, alguns pontos fundamentais associados ao processo de amadurecimento representado: modificamo-nos no contato com o outro. É no dialogismo (BAKHTIN, 2014) que podemos vislumbrar o outro e, nesse processo, imprimir, por meio da responsividade, na relação dialógica, nossas perspectivas em relação ao outro.

Em “Além do bastidor”, o título já indica um possível caminho de alteração da realidade das personagens. O bastidor, objeto de madeira no qual se prende o tecido para mantê-lo firme é um círculo pequeno e fechado. Notamos, então, que algo, na narrativa, será conduzido para além desse pequeno círculo.

A narrativa é iniciada com uma das duas personagens decidindo o que irá bordar. Em meio às dúvidas, uma única certeza: a cor verde: "Começou com linha verde. Não sabia o que bordar, mas tinha certeza do verde, verde brilhante" (COLASANTI, 2015, p. 16). Logo, surge uma forma no tecido preso ao bastidor, o capim: "Um capim alto, com as pontas bordadas como se olhasse para alguma coisa" (COLASANTI, 2015, p. 16). O cenário que começa a tomar forma não é planejado e simplesmente surge das mãos da personagem, mas cada elemento tem sua força e 
importância assim como o capim, que parece ter autonomia no cenário que está sendo construído.

O jardim que se origina do bordado é feito todo da mesma maneira: surge espontaneamente das mãos da personagem, que: "[...] Obedecia às suas mãos, obedecia ao seu próprio jeito, e surgia como se no orvalho da noite se fizesse a brotação" (COLASANTI, 2015, p. 16). Atendendo, então, à sua própria vontade, o bordado toma forma. A evolução no cenário, contudo, é bastante perceptível, já que é comparada com a brotação que surge no orvalho da noite, e que, no amanhecer, já permite que se olhe para outra cena, diferente da que se via antes da noite cair.

O exercício de bordar da personagem é cotidiano, como se pode perceber conforme o trabalho vai ganhando forma: "Toda manhã a menina corria para o bastidor, olhava, sorria, e acrescentava mais um pássaro, uma abelha, um grilo escondido atrás de uma haste" (COLASANTI, 2015, p. 16). É, também, um ato individual e feliz, pois ela o faz de modo voluntário e se sente satisfeita com os resultados: a cada elemento que vai surgindo, ela se sente mais feliz.

A menina adentra no universo construído por suas próprias mãos e nada mais a interessa: "O sol brilhava no bordado da menina. E era tão lindo o jardim, que ela começou a gostar dele mais do que de qualquer outra coisa" (COLASANTI, 2015, p. 16).

Há, repentinamente, uma alteração no uso do verbo, que, até então, era flexionado no pretérito imperfeito, dando uma ideia de vagarosidade ao tempo da narrativa, para pretérito perfeito: "Foi no dia da árvore" (COLASANTI, 2015, p. 16). A mudança repentina na forma verbal indica que algo definitivo irá acontecer. A personagem estava finalizando o bordado e precisava bordar a única coisa que ainda faltava, os frutos: "Bordou uma fruta roxa, brilhante, como ela nunca tinha visto. E outra, e outra, até a árvore ficar carregada, até a árvore ficar rica, e sua boca se encher do desejo daquela fruta nunca provada" (COLASANTI, 2015, p. 16). Da fruta que surgiu no bordado, roxa e brilhante, ela nunca tinha provado.

A fruta bordada a conduz para um mundo de descoberta. Provado esse novo sabor, todos os dias, a personagem busca por ele, descendo ao seu bordado. Passeava pelo mundo criado por suas mãos. No seu mundo, brincava e descobria coisas novas. 
Cotidianamente, bordava algo que desejava, e, depois, interagia com esse elemento, fosse ele um animal ou uma planta:

\footnotetext{
Agora que já tinha o caminho, todo dia a menina descia para o bordado. Escolhia primeiro aquilo que gostaria de ver, uma borboleta, um louva-deus. Bordava com cuidado, depois descia pela linha para as costas do inseto, e voava com ele, e pousava nas flores, e ria e brincava e deitava na grama. (COLASANTI, 2015, p. 16-7)
}

É possível notar uma intertextualidade com a cena da expulsão de Adão e Eva do Jardim do Éden. Tal qual na história bíblica, há um jardim enquanto pano de fundo para o desenrolar da diegese. A diferença é que em "Além do bastidor" a personagem sai do seu mundo e mergulha naquele, sem a parceria de um homem e sem ser retirada da costela dele, mas bordando o que deseja. Do mesmo modo, ao provar da fruta que tanto deseja, não é expulsa desse mundo, pois não comete uma transgressão. Ao saciar seu desejo, sua intimidade com o mundo criado por ela própria torna-se ainda maior e ela passeia livremente em seu jardim percorrendo, diariamente, o caminho pelo fio que vincula o mundo fora do bastidor e o mundo dentro do bastidor.

Percebe-se, ainda, a abordagem do ato de bordar como um rito de passagem. $\mathrm{O}$ narrador refere-se à pessoa que está bordando como menina, mas ela passa por uma transformação ao experimentar do fruto tão desejado, e do qual prova até se sentir saciada: “A menina não soube como aconteceu. Quando viu, já estava a cavalo do galho mais alto da árvore, catando as frutas e limpando o caldo que lhe escorria da boca" (COLASANTI, 2015, p. 16).

É a linha que a mantém na confluência entre a realidade e o desejo. Nota-se, então, a menção ao bordado, mais especificamente, à linha, elemento crucial para essa atividade, como recurso para a personagem se transfigurar de pessoa humana a elemento que faz parte do tecido.

A diegese se encerra quando a segunda personagem do conto, a irmã da menina que borda, observa-a imersa no bordado, acariciando uma garça, achou a cena tão bonita que faltava unicamente a irmã fazer parte dele para que fosse completo.

Há, então, um contraponto com a história bíblica com a qual a narrativa dialoga: se Deus expulsou definitivamente Eva do paraíso quando esta prova do fruto proibido, a irmã a mantém ali para sempre quando borda a irmã no jardim e, na sequência, corta a linha que vinculava os dois mundos. Não se pode dizer, contudo, que o final é feliz, pois 
o rosto da personagem está oculto e não se pode perceber sua expressão: “Quis bordar o rosto, mas estava escondido pela sombra" (COLASANTI, 2015, p. 16).

O tecer, em "Além do bastidor", expressa o retorno da personagem ao seu próprio jardim. Ela imagina e constrói seu próprio universo. A intertextualidade com as passagens do terceiro capítulo do livro de "Gênesis" que relata sobre a expulsão de Adão e Eva do jardim do Éden, o ato de experimentar de um fruto desejado e com a consequência dessa experiência, se encontra com o mito que explica a origem do bordado:

Desde que Adán y Eva fueron conscientes de que estaban desnudos hubo el hombre de vestirse; entre el pudor y lavulnerabilidad ante las inclemencias de la naturaleza, le correspondió al hombre primitivo ponerse a la tarea de remediar la desnudez, y a sus descendientes, la de explicarse los logros de una de las actividades humanas más antiguas: el hilar con un instrumento que existe desde el Neolítico: el huso. Así, entre los mitos que explican lo más antiguo encontramos el origen y la causa de esta tarea humana compleja, que consiste en transformar materiales fibrosos de la naturaleza en finos hilos que, a través de su colocación en urdimbres y tramas, se convierten en telas. (VALLE, 2012, p. 2)

Para Adão e Eva, a necessidade de bordar surge quando se envergonham da nudez e procuram uma maneira de esconder seu corpo. Logo na sequência, a punição por transgredirem uma regra é a expulsão do paraíso. Já a personagem, após provar do fruto desejado, é costurada ali pelas mãos da irmã.

O ato de tecer está vinculado a uma gama de valores simbólicos por meio dos quais o homem questiona "[...] los grandes temas que el hombre se preguntó y se sigue preguntando, a las conceptualizaciones sobre la vida, la muerte, el destino, la religión, la vida social etc." (VALLE, 2012, p. 2). Retomando o título, então, “Além do bastidor", nota-se que o "além" de que trata o título é justamente ao ato de migrar para dentro do bastidor. Ele deixa de ser somente um objeto para firmar o tecido e passa a ser os limites do universo maravilhoso criador pela personagem.

Outro mito com o qual "Além do bastidor" parece dialogar é o das Moiras. As Moiras são três irmãs, Cloto, Láquesis e Átropos, que, quase cegas, são responsáveis por tecer o destino dos deuses e dos homens, decidindo a sorte de cada um, a duração da vida e a quantidade de sofrimentos. Elas são: “[...] a personificação do destino individual, da 'parcela' que toca a cada um neste mundo. Originariamente, cada ser 
humano tinha a sua moîra, a saber, 'sua parte, seu quinhão', de vida, de felicidade, de desgraça” (BRANDÃO, 1986: 230).

As Moiras produzem belas tapeçarias e cada fio representa a vida de um indivíduo. Quando o fio é cortado, o dono daquela vida morre. Cloto vem do grego fiar e ela tece a teia do destino; Láquesis, de sortear; ela decide o fio que será cortado, e Átropos, sem volta, corta o fio que culminará na morte. O mito das Moiras revela: “[...] a existência da fatalidade, da sina no destino humano, algo que o grego não podia evitar; restava a ele se debater, com coragem, areté, numa luta incessante" (PASTORE, 2012, p. 113).

É possível perceber o diálogo com o mito das Moiras em “Além do bastidor", pois, ao bordar, a personagem altera o tecido, mas modifica sua própria vida, que é ressignificada. Láquesis, na figura da irmã, decide quando cortar o tecido e, assim como Átropos, corta o fio e decide o destino da irmã, que não morre, mas fica encerrada naquele universo. Ela se apaixona tanto pelo fruto de seu trabalho que parece revelar sua humanidade: ao provar do fruto desejado, tal como Eva, no Éden, já não pode mais voltar a seu lugar de origem; seu lugar é ali, no mundo que originou. Sua irmã, ao vê-la ali debruçada, corta a linha, e encerra, assim como Átropos, o fio que ligava a irmã ao estado anterior. Antes, tecelã, e, agora, tecido, ao se revelar humana, ela fará parte da tapeçaria.

"Fio após fio" também tem duas irmãs como personagens. Neste conto, ao contrário do primeiro, as personagens são nomeadas: Nemésia e Gloxínia. O espaço no qual a história se desenrola é o castelo no qual as duas vivem. É na torre do castelo que elas bordam, todas as tardes: "Todas as tardes, na torre mais alta do castelo de vidro, Nemésia e Gloxínia bordavam" (COLASANTI, 2015, p. 27). Nota-se, então, que o bordado é posto como uma atividade compartilhada, já que elas bordam juntas.

A oração que inaugura a narrativa remete ao lugar em que elas estão bordando, uma torre de vidro, que é um material transparente, dando a ideia de que é possível ver, do lado de fora, o que elas bordam, e, do mesmo modo, elas têm dimensão do que acontece no mundo externo. Estando as duas na torre mais alta desse castelo, assinala-se uma posição de superioridade. Ainda na primeira oração percebe-se que o bordado era uma atividade cotidiana, já que, juntas, as irmãs bordam todas as tardes. O próprio título alude ao cotidiano, pois o fio após fio é posto como uma atividade em que algo é 
construído de modo muito devagar, etapa por etapa, como se o bordado ao qual dão origem não pudesse ser acelerado.

Na segunda oração tem-se ideia do que está sendo produzido: um longo manto branco que somente uma delas iria utilizar. Do mesmo modo, não há referência acerca de qual das duas o utilizaria: "Longo era o manto de seda branca que as duas fadas floresciam e que uma haveria de usar" (COLASANTI, 2015, p. 27). As duas, então, não são princesas, como se espera, já que elas moram em um castelo, e, sim, fadas. As fadas, como explica Nelly Novaes Coelho (1987), são seres mágicos da mitologia celta: "Foi no seio do povo celta que nasceram as fadas. Ou melhor, foi na criação poética céltico-bretã que surgiram as primeiras mulheres sobrenaturais a darem origem à linhagem das fadas" (COELHO, 1987, p. 31).

$\mathrm{O}$ início da narrativa alude à competição entre as duas, pois não se determina previamente qual delas utilizaria o manto. Do mesmo modo, não se explicam as regras para se decidir quem ficaria com ele. Os nomes das duas fadas são nomes de espécies de flores, Gloxínia e Nemésia, e o florir é posto como ação das duas fadas, quando se narra que elas floresciam o manto.

As duas irmãs têm diferenças entre si no que se refere ao modo de bordar: Gloxínia nunca está satisfeita com seu trabalho, e, diariamente, o desmancha. Já Nemésia segue firme em seu trabalho:

Mas Gloxínia, nunca satisfeita com seu trabalho, desmanchava ao fim de cada dia o que tinha feito, para recomeçar no dia seguinte. Nemésia, gestos seguros, desenhava flores e folhas de um jardim em que todas as pétalas eram irmãs, e a cada dia arrematava o ponto mais adiante. (COLASANTI, 2015, p. 27)

As duas, cada uma trabalhando a seu modo: Nemésia bordando incansavelmente, dando forma a um jardim, e Gloxínia desmanchando e impedindo cada avanço, sem ver correr os dias. A insatisfação de Gloxínia é tanta que seus dedos se machucam enquanto ela desmanchava o tecido. Assim, o tecido fica sujo de sangue. Já a irmã não se abala e o manto branco vai sendo substituído pelo bordado: "Fio após fio feriam-se os dedos de Gloxínia de tanto desmanchar. Sujava-se o pano. Os dedos de Nemésia, tranquilos, brotavam o manto branco" (COLASANTI, 2015, p. 27). Enquanto o lado do bordado de uma irmã fica sujo de sangue, o da outra vai sendo tomado pelas 
flores. Nota-se que a linguagem utilizada remete novamente à floração quando se narra que os dedos de Nemésia brotavam o manto.

Ao perceber que a linha se findava, Gloxínia nota que não bordou um ramo sequer. Conclui, então, que a irmã ficaria com o manto: "Caberia à irmã acabar o manto e ficar com ele, sem que ela a nada tivesse direito por seus esforços" (COLASANTI, 2015, p. 27). Ela entende que a única maneira de tentar ter direito ao manto é abandonar a busca pela perfeição e fazer o trabalho conforme fosse possível: "De nada adiantava agora procurar a perfeição. Abandonando por um instante a tentativa de suas pétalas, Gloxínia aproveitou o último fio para bordar sobre a seda, letra por letra, a palavra mágica” (COLASANTI, 2015, p. 27). Não se diz qual é a palavra mágica, mas é ela, a palavra bordada, que faz com que haja a transfiguração do corpo da personagem Nemésia, ela é transformada em aranha assim que Gloxínia termina de bordar a palavra.

A transformação de Nemésia em aranha permite que Gloxínia tenha a linha necessária para terminar o bordado: "Paciente, Nemésia teceu o primeiro fio. Que na agulha de Gloxínia revelou-se perfeito, permitindo um bordado certo sem precisar a irmã recorrer à tesoura" (COLASANTI, 2015, p. 27). Pela primeira vez, Gloxínia borda em continuidade, sem desmanchar seu próprio trabalho, pois o fio tecido pela irmã se revela perfeito. Passa, então, os dias e as noites bordando, encantada pelo fio e com o resultado de seu trabalho: "Colhia o fio da teia mais próxima e logo mergulhava a agulha cantando na cadência dos pontos obedientes (COLASANTI, 2015, p. 27-8)”"

Fiel ao bordado, a fada passa dias e dias sem necessidade de recorrer a outras atividades. A tarefa, contudo, fez com que Gloxínia deixasse de notar a presença da irmã, fornecedora de seu fio, e se prendesse somente ao resultado de seu bordado: "Fio após fio esqueceu-se da irmã. Havia linha, o bordado enriquecia, e Gloxínia trabalhava feliz no passar dos anos" (COLASANTI, 2015, p. 28). Seu fascínio, então, faz com que ela se esqueça completamente de sua irmã: o fio por ela ofertado é sua única preocupação.

Finalizado o bordado, chegou o dia em que Gloxínia finalmente usaria o manto perfeito. A irmã, transformada em uma aranha, não foi sequer lembrada. Esta se preparava para o momento em que se apresentaria e surpreenderia a corte:

Chegou o dia do último ponto. Gloxínia acabou uma pétala, arrematou um espinho, e percebeu num sorriso que nada mais havia para bordar; a 
primavera desabrochava no manto e a seda desaparecia debaixo das ramagens. Guardada a agulha, Gloxínia levantou-se. Usaria o manto, surpreenderia enfim a corte. Prendeu as fitas largas no pescoço, ajeitou a cauda e virou-se para a porta. (COLASANTI, 2015, p. 28)

Ao voltar-se para a porta, contudo, Gloxínia não notou que o trabalho de anos realizado ao lado da irmã havia tomado todo o quarto que habitavam. As teias da irmã, a bordadeira paciente, estão por todos os lados, e, em vão, Gloxínia procurou a saída. Presa no emaranhado de linhas, ela os rasga, mas logo se vê presa novamente. "Mas onde estava a porta? Ao redor de Gloxínia, as teias de Nemésia. Teia encostada em outra teia, que Gloxínia rasgava sem chegar a lugar algum, somente a outras e mais teias" (COLASANTI, 2015, p. 28).

Nemésia já está do lado de fora da corte, bordando, quando a irmã percebe que ficará presa ali para sempre: “Ao redor da corte, ao redor das salas, ao redor do castelo e dos jardins, lá fora fiava e tecia a paciente Nemésia, esquecida da corte, esquecida da irmã para sempre prisioneira do seu casulo de prata" (COLASANTI, 2015, p. 28). As linhas de Nemésia, então, aprisionam a irmã no quarto em que, por anos, bordaram juntas. Nenhuma das duas usaria o manto, cada uma aprisionada de uma forma distinta.

"Fio a fio", então, parece dialogar com o mito de Aracne. Aracne era filha de Ídmon, um rico tintureiro de Cólofon. Ela bordava e tecia de forma tão perfeita que as ninfas dos bosques vinham para contemplá-la. Era considerada discípula de Atena, que, justamente, era a deusa dos trabalhos da fiação, da tecelagem e do bordado. Aracne, vaidosa, desafiou Atena, que aceitou: mas apareceu sob a forma de uma anciã, aconselhando-a a que depusesse sua hýbris, sua démesure, seu descomedimento, que não ultrapassasse o métron e que fosse mais comedida, porque os deuses não admitiam competição com os mortais. A jovem, em resposta, insultou a anciã. Ao ser vencida, pois o trabalho de Aracne era perfeito, Atena a transforma em aranha, que é obrigada a tecer pelo resto da vida (BRANDÃO, 1986).

Também parece haver diálogo, em "Fio a fio", com a narrativa sobre Penélope, da mitologia grega. Penélope, assim como Gloxínia, desmanchava diariamente seu bordado, mas, ao contrário desta, aquela desmancha o trabalho para afastar seus pretendentes, pois havia prometido que se casaria assim que o bordado estivesse pronto. Gloxínia, por sua vez, não se desfaz de seu bordado motivada por um homem, e sim porque ela própria está insatisfeita com o resultado de sua atividade. 
Retomando Bakhtin (2014) e a presença de outras vozes no discurso, percebe-se que essa manifestação pode ser direta e evidente ou interna, indivisível, e é nesse caso que se encontra a presença dos mitos nos contos aqui analisados. Esse dialogismo, que aparece imbricado de questionamento em relação ao discurso sobre o lugar social da mulher, tão presente nos contos de fadas tradicionais, é possível devido ao terceiro conceito de dialogismo, que postula que o sujeito apreende os discursos de acordo com a realidade heterogênea na qual está imerso e em contato, ou seja, a multiplicidade de vozes sociais com as quais tem contato. É essa heterogeneidade de vozes que permite que o sujeito reelabore, durante sua existência, discursos, pois cada experiência é única.

As relações dialógicas, das quais Bakhtin se ocupa, não dizem respeito ao diálogo face a face, mas, sim, às posições sociais que a interação evidencia. No caso da obra de Colasanti, nota-se o que José Luiz Fiorin (2016) chama de segundo conceito de dialogismo na obra de Bakhtin. Bakhtin define que uma das formas por meio das quais o dialogismo se manifesta é enquanto forma composicional, que diz respeito aos modos por meio dos quais outras vozes estão incorporadas no discurso. As vozes incorporadas nos textos analisados são, justamente, os textos provenientes das narrativas fundadoras, como de Adão e Eva, das Moiras, ou mesmo o mito de Aracne.

\section{Referências}

BAKHTIN, Mikhail Mikhailovich. Marxismo e filosofia da linguagem: problemas fundamentais do método sociológico na ciência da linguagem. Tradução de Michel Lahud et al. 16. ed. São Paulo: Hucitec, 2014.

BEAUVOIR, Simone. O segundo sexo. Tradução de Sérgio Milliet. 2. ed. Rio de Janeiro: Nova Fronteira, 2009.

BELLIN, Greicy Pinto. A crítica literária feminista e os estudos de gênero: um passeio pelo território selvagem. Revista FronteiraZ, São Paulo, v. 1, n. 7, p. 1-11, 2011.

BRANDÃO, Junito de Souza. Mitologia grega. Vol. I. Petrópolis: Vozes, 1986.

COELHO, Nelly Novaes. O conto de fadas. São Paulo: Ática, 1987.

COLASANTI, Marina. Mais de 100 histórias maravilhosas. Ilustrações de Marina Colasanti. São Paulo: Global, 2015. 
COSTA, Suely Gomes. "Movimentos feministas, feminismos". Rev. Estud. Fem., Florianópolis, v. 12, n. spe, p. 23-36, Dec. 2004. Disponível em: http://www.scielo.br/scielo.php?script=sci_arttext\&pid=S0104-

026X2004000300003\&lng=en\&nrm=iso. Acesso em: 11 jul. 2018.

FIORIN, José Luiz. Introdução ao pensamento de Bakhtin. 2. ed. São Paulo: Contexto, 2016.

FLORES, Hilda Agnes Hübner. "O helenismo e a mulher". In: FLORES, Moacyr (org). Mundo greco-romano: arte, mitologia e sociedade. Porto Alegre: EDIPUCRS, 2000. (Coleção História, 38). p. 69-89.

PASTORE, Jassanan Amoroso Dias. "O caos, o acaso e o trágico”. Ide (São Paulo), São Paulo, v. 35, n. 54, p. 109-125, jul. $2012 . \quad$ Disponível em http://pepsic.bvsalud.org/scielo.php?script=sci_arttext\&pid=S0101-

31062012000100011\&lng=pt\&nrm=iso. Acesso em: 5 maio 2019.

SHOWALTER, Elaine. A crítica feminista no território selvagem. Tradução de Deise Amaral. In: HOLLANDA, Heloísa Buarque de (Org.). Tendências e impasses: o feminismo como crítica da cultura. Rio de Janeiro: Rocco, 1994

VALLE, Nieves Rodríguez. "Coser y cantar": El hilar como espacio de latransmisión oral, la lira que le canta y elrefrán que lo sentencia. Olivar, 13 (18), 235-253. 2012. En Memoria Académica. Disponível em: http://www.memoria.fahce.unlp.edu.ar/art_revistas/pr.5833/pr.5833.pdf. Acesso em 23 jul. 2018.

Recebido em: 08/08/2019

Aceito em: 15/05/2020

\footnotetext{
${ }^{1}$ Em tese de doutorado sobre a literatura juvenil escrita por mulheres no período de 1979 a 1984 , defendemos a tese de que a literatura juvenil incorpora o discurso feminista que estava em evidência no referido período. CORDEIRO, Maisa Barbosa da Silva. Feminismo e gênero: a literatura juvenil escrita por mulheres (1979-1984). Três Lagoas-MS: Tese de Doutorado em Estudos Literários (UFMS), 2019.
} 